\title{
A FICÇÃO DE MARÇAL AQUINO: \\ UMA REPRESENTAÇÃO DA SOCIEDADE BRASILEIRA CONTEMPORÂNEA
}

\author{
Rosana Cristina Zanelatto Santos ${ }^{1}$ \\ Thais Ferreira Pompêo de Camargo ${ }^{2}$
}

Resumo: Este trabalho se propõe analisar o texto O Invasor, de Marçal Aquino, tanto o livro quanto a narrativa cinematográfica, comparativamente. Foram selecionados trechos de ambos com o objetivo de explicitar como se articulam as linguagens de cada suporte, para conseguir atingir os efeitos emocionais e estéticos adequados a cada público. Em última instância, buscase demonstrar como uma narrativa ilumina/amplia a outra e que a partir dessa interseção é possível penetrar em camadas mais profundas do texto de Marçal Aquino, desvelando o que Tony Belotto sinaliza desde a contracapa do livro: "Cuidado com as prosas aparentemente simples e as novelas enganosamente curtas. Elas podem ser uma armadilha para enredar o leitor numa grande história".

Palavras-Chaves: Marçal Aquino; Lliteratura brasileira contemporânea; Cinema brasileiro; Comparação.

\begin{abstract}
This study aims to analyze the text $O$ Invasor, written by Marçal Aquino, both the film narrative and the book, comparatively. Extracts of both texts were selected with the aim to clarify the articulation of languages in each support, in order to achieve appropriate emotional and aesthetic effects for each audience. Ultimately, we seek to demonstrate how a narrative illuminates/enlarges the other and from that intersection it is possible to penetrate into the deeper layers of Marçal Aquino's text, unveiling what Tony Belotto signals since the cover of the book: "Beware with the apparently simple proses and deceptively short novels. They could be a trap to entangle the reader in a greater story".
\end{abstract}

Keywords: Marçal Aquino; Contemporary Brazilian literature; Brazilian cinema; Comparison.

\footnotetext{
${ }^{1}$ Professora da Universidade Federal de Mato Grosso do Sul. E-mail: rzanel@terra.com.br

${ }^{2}$ Mestranda em Estudos de Linguagens - UFMS. E-mail: thais.pompeo@gmail.com
} 
$\mathrm{Na}$ medida em que sou um escritor realista e trato de situações da realidade, seria uma fraude se eu não abordasse a violência; eu pretendo, ao abordar a violência, para mostrar e refletir, através da ficção, sobre ela [...] acho que nosso papel como escritores, cineastas e outros é discutir essa realidade colocar o dedo na ferida que dói, mas é necessário. (ENTREVISTA com Marçal Aquino, 2013, p. 39)

\section{Introdução}

Para construir os alicerces deste artigo, se fazem necessários alguns adendos com relação ao escritor Marçal Aquino, autor de $O$ Invasor. Ele se define como realista, postulando-se como dono de um texto com forte caráter de observação e crítica social, o que nos leva a cogitar que parte de sua construção como escritor esteja calcado em seu passado como jornalista, mais precisamente como jornalista policial. ${ }^{3}$

A narrativa de Aquino é crua e dura, com pontos de contato com o jornalismo policial e o estilo enxuto (quase árido) de escritores como o norteamericano Ernest Hemingway, além de boas pitadas de um humor sarcástico. É nessa linguagem descarnada, sem rodeios e bruta, na medida em que busca a verossimilhança em meio à dureza da realidade, que o diretor de cinema Beto Brant ${ }^{4}$ encontrou afinidade estética com os textos de Aquino.

O narrador das histórias de Aquino carrega consigo duas propostas caras a Italo Calvino nas suas Seis propostas para o próximo milênio: a rapidez e a exatidão. Como rapidez, o crítico italiano define: "[É a] economia narrativa em que os acontecimentos, independente de sua duração, se tornam punctiformes, interligados por segmentos retilíneos, num desenho em

\footnotetext{
${ }^{3}$ Nascido em Amparo (SP) em 1958, Aquino é graduado em Jornalismo (PUC/Campinas, 1983). Saindo do interior, muda-se para a capital paulista em 1984, passando a trabalhar como jornalista na Gazeta Esportiva e em O Estado de S. Paulo. Também atuou como jornalista policial no Jornal da Tarde.

${ }^{4}$ Nascido em Jundiaí (SP) em 1964, Brant estudou cinema na FAAP (São Paulo). Nas décadas de 1980 e 1990, dedicou-se à feitura de videoclipes e de curtas. Seu primeiro longametragem foi Os matadores (1997), filmado na fronteira Brasil-Paraguai, com roteiro de Marçal Aquino, com quem passou a manter profícuas relações de trabalho.
} 
ziguezagues que corresponde a um movimento ininterrupto" (CALVINO, 1990, p. 48). Sobre a exatidão, ele afirma ser um "[...] esforço de adequação minuciosa do escrito com o não escrito, da totalidade do dizível com o não dizível" (CALVINO, 1990, p. 88). Ambos os aspectos são estendíveis ao cinema de Brant, com o roteiro de Aquino. Durante o percurso deste artigo, demonstraremos como isso se desenrola.

A primeira experiência de Marçal Aquino como roteirista de cinema deuse pela adaptação da própria obra para as películas cinematográficas, com Brant: trata-se do conto "Os Matadores". Foi um encontro artístico-estético que rendeu cinco outras parcerias, em geral no sentido texto literário - cinema. $A$ terceira delas, O Invasor, de 2002, rompeu essa direção; quando Brant decidiu filmar o texto de Aquino, o livro existia apenas até o quarto capítulo. A partir do quinto, foi criado o roteiro, sem o suporte literário. Ao fim do filme, o próprio Aquino adaptou o roteiro para a literatura, sendo ambos lançados juntos, livro e película, em 2002. Essa peculiaridade de O Invasor pode justificar a velocidade frenética do ritmo do livro, típica de um filme de ação hollywoodiano, contudo, com uma temática arraigada nos maiores problemas sociais da sociedade brasileira contemporânea.

\section{Literatura e cinema: a reflexão pelo choque}

O tema central de O Invasor surgiu de uma observação de Marçal Aquino de que parte da elite financeira brasileira não temia a violência urbana, porque tinha a sensação de que estaria protegida/isolada via sistemas de segurança. O escritor, ainda jornalista, percebeu nesse discurso, além do individualismo, a alienação. Nele, não havia a consciência do lugar social dos seguranças, das empregadas domésticas ou das babás. Indo além, esse discurso trazia implícito o senso comum de que a violência é um mal originado fora dos bairros mais abastados da cidade de São Paulo, querendo se infiltrar neles como um ser alienígena, vindo de fora e não habitando as entranhas das elites brasileiras. 
Em linhas gerais, $O$ Invasor conta a história de dois engenheiros de uma construtora que contratam um matador de aluguel para eliminar o terceiro sócio, pois este não quer entrar em uma obra pública superfaturada. 0 romance é ambientado na cidade de São Paulo, sendo carregado de descrições realistas do dia a dia da maior metrópole do Brasil: é a periferia com ruas deterioradas, botecos esquálidos e casas traumatizadas, característica de uma urbanidade/de um espaço esgarçado que pulula na prosa brasileira contemporânea (PINTO, 2004, p. 82).

Ao tomar esse quadro narrativo como mote, Beto Brant se põe como observador e crítico social, selecionando peças do quebra-cabeça que é a modernidade e entregando-as para o espectador (re)montá-lo. Assim como Aquino, Brant tem um estilo que rompe com o mainstream, construindo narrativas nada óbvias, com um perfume indie pop capaz de fisgar 0 espectador.

Tanto Aquino quanto Brant preferem o choque a poupar o leitor/o espectador. Embora as imagens sejam de uma nitidez dura e crua, elas embaçam, ficam foscas e confusas quando se completa o ciclo semântico na cabeça do leitor/do espectador. Isso se dá pelo choque: ambos os artistas não esvaziam ou abrandam as relações com informações, nem se preocupam em justificar nada. Vão direto ao ponto, sem rodeios, sem sofismas. A concatenação das ações fica a cargo do leitor/do espectador. É por isso que eles podem ser chamados de narradores, no sentido usado por Walter Benjamin (1983, p. 61): "Já é metade da arte de narrar, liberar uma história de explicação à medida que ela é reproduzida".

Vale a pena prestar atenção no jogo criado por Aquino entre a linguagem jornalística/informativa e a do escritor/narrador: o texto carrega a estética descarnada do jornalismo, mas isso é só aparência, uma estratégia para enredar o leitor em uma narrativa intrincada e com muitas camadas, haja vista o uso preciso de adjetivos e a profundidade sem remorsos ou remansos dos personagens.

Para a tradução entre os suportes, Beto Brant utiliza uma solução estilística semelhante à de Aquino: ele faz uso da câmera na mão, instável, 
como a dos documentários e das reportagens jornalísticas. Esse procedimento traz emoção e tragicidade à narrativa cinematográfica.

Pensar nas características narrativas, nas funções e nas formas que confluem e refluem nos dois meios - o livro e o filme - é o que se propõe Thais Diniz (2005, p. 21):

O romancista dispõe de um único meio de expressão, que é a linguagem verbal. Esta relaciona-se com o pensamento, mas pode também sugerir efeitos sensórios, impressões de espaço, aparência visual, cor e luz. Já o cineasta, além da linguagem verbal, escrita, como em títulos e legendas, ou oral, como nos diálogos, dispõe de outros meios de expressão, tais como música e imagem visual. Porém o pensamento, mais facilmente associável à linguagem verbal, mostra-se menos acessível aos recursos típicos do cinema [...] Na verdade, nuances de tom, humor, e a expressão de sentimentos, permanecem, às vezes, apenas implícitos, cabendo ao espectador interpretá-los.

Pensemos, pois, no texto literário $O$ Invasor. $O$ narrador está em primeira pessoa, Ivan, um dos sócios à procura de um matador. Essa opção faz com que o leitor entre na atmosfera caótica que se torna a vida do personagem, estabelecendo um clima que é reforçado pelo cenário à sua volta, como descrito por ele: a São Paulo de Ivan é nervosa, violenta, constipada, decadente, inviável.

O ruído dos caminhões e carros que trafegavam pela Marginal Tietê entrou pelo vitrô do banheiro junto com a claridade da manhã. Enquanto urinava, espiei o céu esbranquiçado de mais um dia poluído na cidade. (AQUINO, 2011, p. 94)

Como afirma Thais Diniz (2005, p. 21), pensamentos são menos acessíveis em filmes. Assim, o roteirista de $O$ Invasor (o próprio Marçal Aquino) opta em retirar o narrador, transferindo sua subjetividade para a forma de gravar e de montar o longa-metragem. Por sua vez, Brant opta por uma câmera fora do tripé, na mão, tensa e veloz: ela é a representação do olhar de Ivan embora não seja uma câmera subjetiva. Esses são dois dos recursos que o roteirista e o diretor usaram para traduzir intersemioticamente o livro para 0 filme. 
Sobre o processo de tradução, Diniz traz à luz a concepção de adaptation proper, ou adaptação criativa, de Brian McFarlane, a prova da capacidade artística do cineasta contra o senso comum de que ele teria que manter fidelidade à obra que originou a película cinematográfica:

Para McFarlane, a tradução de elementos como sensações, sentimentos e pensamentos dos personagens, incluindo a atmosfera ou o humor de toda uma situação - caracteriza o processo de 'adaptation proper' ou adaptação criativa, constituindo a prova de toque da arte do cineasta. (DINIZ, 2005, p. 15)

Para a transposição da primeira cena do filme, Brant e Aquino fizeram a adaptação criativa ao invés de manter a fidelidade ao texto literário. Essa opção foi usada, pois o capítulo é basicamente regido pelos pensamentos de Ivan, trazendo à tona suas sensações e descrevendo, sob o seu olhar, o bairro de periferia onde acontece o primeiro encontro com o assassino de aluguel. Trata-se de um bar "esquálido", com uma atmosfera "medonha".

\begin{abstract}
Mesmo seguindo as indicações de Anísio, demoramos um bocado para encontrar o bar, numa rua estreita e escura da Zona Leste. Um lugar medonho. Estacionei perto do que parecia ser uma fábrica abandonada, um galpão enorme e cinzento, com as paredes pichadas e vitrôs com vidros quebrados. Alaor continuou imóvel, segurando a pasta no colo. Tínhamos trocado meia dúzia de frases, se tanto, no trajeto até ali [...] Então ali estávamos, naquele lugar sem nenhuma vocação para cartão-postal. Fechei o carro, acionei o alarme e caminhamos até o bar, do outro lado da rua. Havia algo de melancólico no calçamento pintado de verde e amarelo, uma lembrança desbotada dos dias de jogos da Seleção na Copa. Era uma noite abafada e, apesar da distância, dava para ouvir o tráfego pesado da Radial Leste [...]. (AQUINO, 2011, p. 1)
\end{abstract}

Para traduzir esse trecho do livro para o cinema, que traz vários elementos importantes do enredo, Brant opta por um plano sequência (sem corte) tenso, que aos poucos descobrimos que é uma câmera subjetiva do ponto de vista de Anísio, o assassino de aluguel.

Enquanto aparecem os créditos iniciais do filme, ouvem-se ruídos de garrafas, do trânsito abafado ao fundo, de vozes, o que sugere que o lugar é 
um bar. Repentinamente, aparece a primeira imagem: um homem pobre de periferia, negro, gritando na rua de uma maneira pouco amistosa. Vemos os personagens Ivan e Giba (no livro, ele se chama Alaor, sendo o único personagem que muda de nome de um suporte para outro) descendo do carro, nervosos, através da câmera tremida e rápida, com zoons in e out, como se fosse o olho ajustando o foco para reconhecer aquelas pessoas. São dadas poucas informações ao espectador.

A câmera segue acompanhando os personagens entrarem no bar, até que eles param em frente à câmera. O espectador é, então, surpreendido, pois se dá conta que está olhando a cena do ponto de vista do assassino de aluguel, o que gera desconforto. São dois minutos tensos, sem cortes. $O$ espectador se vê cara a cara com os personagens, visivelmente desconfortáveis. Além disso, não vê o rosto da pessoa de voz rude que fala do outro lado da mesa e que provoca tensão nos personagens. Todos esses artifícios, típicos da narrativa cinematográfica, são os responsáveis por criar a atmosfera de medo, abandono e violência que, no livro, são construídos, principalmente, pelos pensamentos de Ivan. O diálogo é todo rarefeito e ágil, criado exclusivamente para a narrativa fílmica: mais seco e rude do que o do livro, apenas entre Giba e Anísio. Sintético, direto ao ponto, conforme transcrito a seguir:

- Você é o Anísio?

- Por que meu, do que que se trata?

- Tô procurando o Anísio. O Norberto me indicou ele pra um serviço.

- E o trampo, tá aí?

- Tá, tá aqui.

- Tá tudo aqui?

- Tá, tá tudo aí.

- E aí, quanto tempo demora?

- Em uma semana eu desosso essa fita. E o cara aí não fala nada? É cana, é ganso, qual que é?

- É meu parceiro, meu sócio, também tá pagando.

- Se não for, é o seguinte, ninguém sai daqui.

- Pode ficar tranquilo, tudo bem. 
Se no livro, Ivan é o narrador, no filme, Giba está no comando do diálogo, dos planos e das próximas ações.

\section{"Ninguém presta" e trilha sonora}

No romance de Marçal de Aquino, os personagens são agressivos, psicologicamente adoecidos e animalizados, em um mundo que paira desequilibrado. E sobre condutas escusas, Alaor/Giba é o professor de Ivan, como um pai que ensina o filho. Isso está bem representado no filme quando, no prostíbulo de luxo no bairro de Pinheiros, Giba, literalmente, conduz Ivan "[...] ao lado podre da vida" (para usar uma fala de Giba), andando com a mão em sua nuca - gesto típico de um pai que leva ao filho. A câmera enfatiza essa ação, numa descrição que não aparece no texto literário.

Essa cena é toda picotada e editada, repetindo a cena da mão de Giba na nuca de Ivan, causando desconforto e reforçando a atmosfera angustiada, em mais um dos exemplos da habilidade de Brant em substituir/adequar por imagens as expressões literárias dos estados emocionais dos personagens.

Mas que não nos enganemos: Ivan não é o mocinho da história; na melhor das hipóteses, é um malfeitor arrependido ou um covarde; ele não teme pelo que fez, mas tem receio de ser pego e de parar na prisão.

Tanto Ivan quanto Giba/Alaor são/têm fachadas de homens honestos em um mundo regido por imagens/pelas aparências. Giba/Alaor é um mau caráter escondido atrás do engenheiro bem sucedido, marido e pai de família, mas que tem uma filosofia de vida peculiar:

O Cícero até pode ter essa cara de sonso, mas, se precisar, ele vira bicho. Basta surgir uma oportunidade [...] No fundo, esse povo quer o seu carro, o seu cargo, o seu dinheiro, as suas roupas. Querem comer a sua mulher, entendeu? É só surgir uma chance. É isso é o que nos vamos fazer com o Estevão:

\footnotetext{
${ }^{5}$ Trecho da trilha musical da cena na qual acham o carro de Estevão, o sócio assassinado. Música produzida por Sabotage e Instituto.
} 
vamos aproveitar a nossa oportunidade antes que ele faça isso primeiro. (AQUINO, 2011, p. 49)

Enquanto no texto literário o caráter de Giba/Alaor é explicitado pelos pensamentos de Ivan, no filme, Brant precisou adicionar algumas cenas para apresentar ao espectador a falsidade e a frieza do personagem, mostrando a faceta de bom marido e pai com uma tomada em que ele brinca com a filha e com a esposa, contando a história dos três porquinhos (numa metáfora dos três sócios, em que o mais esperto seria ele), deixando que o observador perceba, nas entrelinhas, seu modo de ser e de viver.

Outro exemplo marcante da habilidade de Beto Brant em substituir/adequar as expressões literárias de estados emocionais pela linguagem cinematográfica é a cena em que Estevão e sua esposa são achados no porta-malas do carro na Zona Sul de São Paulo. Eis o trecho no romance:

O carro de Estevão foi localizado às três horas da tarde da quinta-feira, no final de uma de terra no extremo sul da cidade. Um homem viu o carro de manha, quando passou a caminho do poço onde os moradores do bairro se abastecem de água [...] O corpo de Estevão estava no porta-malas, com uma bala na cabeça. Embaixo dele, a polícia encontrou o cadáver de Silvana, com dois tiros no peito. Fazia menos de setenta e duas horas que eu e Alaor tínhamos contratado Anísio. (AQUINO, 2011, p. 53)

Mais adiante, Ivan descreve a cena do velório:

Em vários momentos, no velório, eu achei que não aguentaria [...] Foi quase impossível fingir dor onde existia nojo. Alaor manteve no rosto durante todo o tempo uma expressão de quem havia sofrido uma grande perda. Um verdadeiro artista [...] Mas o show ainda tinha mais atrações: ele pegou um lenço do paletó e só então me dei conta das lágrimas em seu rosto. Ele voltou para perto de onde eu estava, me abraçou e soluçou, com a cabeça apoiada em meu ombro. Naquela hora, eu quis sumir dali. Depois que conteve o choro, Alaor murmurou em meu ouvido: 'Venha, vamos dar uma palavra de apoio à nossa nova sócia'. E me puxou na direção de Marina. (AQUINO, 2011, p. 60-61) 
No filme, são feitas algumas mudanças/adequações significativas para que ambas as cenas tenham a força dramática encenada pela fala de Ivan, o narrador em primeira pessoa. Inicialmente, o diretor muda o horário em que foi encontrado o carro de Estevão: da tarde para a madrugada, um horário difuso, fantasmagórico. Além disso, coloca os dois sócios juntos não apenas no velório, mas também no local onde foram encontrados os corpos.

O cenário do filme é um lugar no meio da madrugada e no meio do nada, de terra batida, parecendo uma rua sem saída. Ao fundo, o carro de Estevão e uma viatura da polícia. Passa, em primeiro plano, o carro do IML. Não há diálogos; o show fica todo por conta do teatro de Giba e da trilha heavy metal, com guitarras e uma voz que urram. A letra reitera: "Bem-vindooo ao pesadelo da realidade [...] Eu, você, a vadia ninguém prestaaa".

A trilha sonora se mantém nas duas próximas cenas, sendo o elemento de fusão entre elas: o velório, seguido da chegada (ou invasão) de Anísio à construtora. Outro elemento fílmico utilizado, tanto para fundir as três cenas como para a dramatização, é a câmara, que volta a ser trabalhada na mão, rápida, tensa. Tanto a trilha como a câmera agitada só desaparecerão da narrativa quando Anísio entrar no escritório de Ivan. Junto com o corte, suspende-se radicalmente a trilha e dá-se fim à instabilidade da imagem. Porém, não é sossego que o diretor busca causar; começa outra onda de tensão: Ivan se desespera ao ver Anísio em seu escritório, e a dramaticidade salta para a interpretação e o diálogo dos atores.

A filosofia de vida de Giba coincide com a de Anísio. Marçal Aquino não passa a mão na cabeça do assassino, tentando justificar suas ações em consequência da miséria ou da pobreza. Anísio quer mais que o combinado; ele quer ficar na empresa: ele se infiltra e pressiona os engenheiros para virar seu segurança e depois seduz a órfã, filha de Estevão, e se torna seu namorado, ou seja, ele pode ser o futuro sócio de Ivan e Giba.

Além dos três personagens ora apresentados, existem ainda: a patricinha alienada e drogada (Marina, filha de Estevão); o delegado corrupto (Norberto); e o servidor público corrupto (Rangel), sujeitos coadjuvantes na construção dessa crônica sem tempo de escrúpulos que é $O$ Invasor. 
No filme, a preocupação com um elo com a realidade para além da verossimilhança reside na participação do rapper Sabotage. Em depoimento, tanto Aquino quanto Brant afirmam a valiosa contribuição de Sabotage para a produção da película. Ele reescreveu todas as falas de Anísio, trazendo um caráter de oralidade das ruas, e ajudou na concepção do personagem junto ao ator Paulo Miklos, fazendo com que essa seja uma das melhores atuações do filme. O rapper trazia a experiência de causa: cresceu na periferia da cidade de São Paulo, passou pela Febem na infância, foi assaltante e gerente de tráfico até encontrar o rap. Ele foi assassinado um ano após o lançamento do filme, em uma emboscada.

\section{Quem é o invasor?}

No decorrer de ambas as narrativas, percebemos que a violência estabelece o elo entre os personagens da trama. Ela é o nó de uma rede de relações acionadas por Giba. Juntam-se a ela temas correlatos (política, ascensão social, arrivismo) e o jogo entre ser e parecer, como numa brincadeira de esconde-esconde.

Marçal Aquino deixa várias perguntas no ar: quem incita a violência? O centro ou a margem? Ao invés de Anísio, não seria Giba/Alaor o verdadeiro, e o mais devastador/violento, invasor? Por que a violência é um tema tão caro, tão contemporâneo a nós?

Segundo o filósofo Giorgio Agamben (2009, p. 62-63),

Contemporâneo é aquele que mantém fixo o olhar no seu tempo, para nele perceber não as luzes, mas o escuro. Todos os tempos são, para quem deles experimenta contemporaneidade, obscuros. Contemporâneo é, justamente, aquele que sabe ver essa obscuridade, que é capaz de escrever mergulhando a pena nas trevas do presente.

O obscuro em nós e em nosso tempo: é isso o que Marçal Aquino enxerga em $O$ Invasor. Se ele escolhe temas tão aparentemente comuns na trama artística, por outro lado, ele não os justifica, nem explica sua opção ou a dos personagens. Cada um que enxergue a sua. $O$ enredo de Aquino tem 
parentesco com o recém-descoberto esquema bilionário de corrupção das maiores empreiteiras do País e que estão sendo pegas na Operação LavaJato. Vale lembrar que o livro começou a ser escrito em 1997, ou seja, há quase 20 anos, e Aquino já direcionava sua pena para uma direção obscura da realidade brasileira, desvelando uma forma de violência pouco falada nos (tele)jornais, aquela que vem de cima para baixo, em um Brasil com histórico secular de indigência.

No final do livro, que se mantém fidedigno à descrição e ao diálogo do filme, o camburão que carrega Ivan encosta em uma casa. Saem dela Anísio e Giba/Alaor, juntos, em direção a ele. O delegado fala: "Resolvam essa merda de uma vez por todas. Se não tivesse gente minha no plantão, vocês estariam fodidos. O cara deu o serviço completo. Agora é com vocês. Eu já fiz tudo que podia" (AQUINO, 2011, p. 122). Era o sócio de Giba no prostíbulo, Norberto, garantindo a continuidade do sistema. Aquino deixa em suspenso mais uma pergunta para o leitor/o espectador: "afinal, quem é o invasor?" 
REFERÊNCIAS

AGAMBEM, Giorgio. O que é o contemporâneo? E outros ensaios. Tradução Vinícius Nicastro Honesko. Chapecó, SC: Argos, 2009.

AQUINO, Marçal. O Invasor. São Paulo: Companhia das Letras, 2011. (Má Companhia).

BENJAMIN, Walter. O Narrador. In: Textos Escolhidos / Walter Benjamin, Max Horkheimer, Theodor W. Adorno, Jürgen Habermas. Tradução José Lino Grünnewald et al. São Paulo: Abril, 1983.

BRANT, Beto. O Invasor. Roteiro: Marçal Aquino, Beto Brant e Renato Ciasca. Produção: Bianca Villar e Renato Ciasca. Gênero: Drama. Elenco: Alexandre Borges, Malu Mader, Marco Ricca, Mariana Ximenes, Paulo Miklos, George Freire. Estúdio: Drama Filmes. Brasil, 2002. Duração: 97 min.

CALVINO, Italo. Seis propostas para o próximo milênio. Tradução Ivo Barroso. São Paulo: Companhia das Letras, 1990.

DINIZ, Thais Flores Nogueira. Literatura e cinema: tradução, hipertextualidade, reciclagem. Belo Horizonte: Faculdade de Letras da UFMG, 2005.

ENTREVISTA com Marçal Aquino. Anais do LITERASUL - 10. Encontro Estadual de Literatura em Mato Grosso do Sul. Campo Grande: UBE - Seção Mato Grosso do Sul, 2013.

PINTO, Manoel da Costa. Literatura Brasileira hoje. São Paulo: Publifolha, 2004. 